\title{
THE ANALYSIS OF EXISTING EXPERIENCE FOR THE ETHNOBOTANICAL INFORMATION SYSTEM
}

\author{
Laman Faig Hamidova \\ Department of System analysis, control and information processing \\ Institute of Information Technology of ANAS \\ $9 A$ B.Vahabzade str., Baku, Azerbaijan, AZ1141 \\ leman.hemidova92@gmail.com
}

\begin{abstract}
Ethnobotanical researches reflect the conventional learning of a region. Over the previous decade, medical plants which used for healing indigenous people has become a significant notion among the people and impacted improvement of scientific and ethnobotanical knowledge and investigations of eliminating health problems. A public database has been based on data assembled from various verifiable sources, including journals, travel records, and treatises on therapeutic plants, composed by explorers, botanists, doctors, researchers who went to the nations during the most recent three centuries. In addition, ethnobotanical data depicted in chronicled natural accumulations and in Ancient and Medieval writings from the inquired district have been incorporated into the database. The databases have to be sufficiently adaptable to illustrate a valuable tool for analysts who need to store and analyze present and past ethnobotanical data from the researched location. The ethnobotanical researches are improved in Azerbaijan day by day. The database is used for informing people about some national plants which are growing in the different region of Azerbaijan. The ethnobotanical databases from different countries are analyzed in this article.

There are used some special methods for comparing the differences among these databases as data mining and text mining. As a first step the suitable databases are gathered for our investigation, then are defined the best information systems that are used in many countries' biologists and scientists and the end is observed advantages and disadvantages of all existing ethnobotanical databases which we researched. The features of information systems are evaluated. The results demonstrated each of databases has its very own quality, but none has turned a standard form for universal research. The reason is very basic: none of these databases enable specialists to include their own information. There is also illustrated sample structure, main tables and key components of the ethnobotanical database.

The obtained results, while a few ethnobotanical databases existing, none are satisfactory answers for worldwide work, and none enable analysts to include their very own information. There is a need brought together all essential properties of existing databases, and creating a free database that encourages ethnobotanical research. Due to the rise and quick improvement in the field of data advances, it has now turned out to be conceivable to digitize, oversee and make ethnobotanical information accessible to a more extensive gathering of people.
\end{abstract}

Keywords: ethnobotanical biodiversity, herbal medicine, medicinal plants, ethnobotanical database, key components, structure, main tables of the ethnobotanical database.

\section{Introduction}

Over a time of four billion years, development has brought about overwhelming biodiversity on earth and has remained the essential power for the advancement of assorted life shapes over the globe [1]. It is assessed that of the aggregate number of life forms going from 7-20 million, just 1.8 million species are logically named. Overwhelmingly, the world's biodiversity alluded to as "biodiversity storage facilities" with remarkable taxon and species assorted variety [1]. Environmental change and human impacts have brought about a phenomenal loss of biodiversity, with an expected 100-1000 overlap speeding up in the annihilation rate of botanical and faunal species contrasted with their normal rate. Shockingly, moderates are looked with a scarcity of information as just $1 \%$ of every single recognized species has been considered past essential classification [2].

Truly, people have depended on biodiversity as an essential wellspring of sustenance, protect and for profound and mental prosperity. Medical plants involve a noteworthy piece of the biodiversity and shape an inseparable connection between natural and social variety. Their co-advancement has delivered neighborhood conventional restorative plant learning and practices. This wide knowledgebase is passed on from age to age, moves as orally like stories, melodies and frames for the manageable misuse and preservation of biodiversity. As indicated by the World Health Or- 
ganization (WHO), $80 \%$ of the populace from various nations relies upon customarily used therapeutic plants for their essential medicinal services [3]. It is evaluated that there are 300,000 plants on the planet of which 75,000 plant species are used as customary medication [4]. As indicated by the writing information, the flora of Azerbaijan comprises of about 5000 plant species, having a place with 1142 genera of 186 families, including 200 endemics of Azerbaijan and 950 endemics of the Caucasus. The types of the flora of Azerbaijan are circulated in 20 phytogeographical locales. Among them, the hilly piece of Nakhchivan emerges as far as species decent variety, with about $60 \%$ of all plant types of the country occurring there, trailed by Greater Caucasus and the Lankaran-Mughan plain [5]. Be that as it may, proceeding natural surroundings annihilation and human-incited ecological changes have prompted the loss of vital therapeutic plants used customarily by indigenous. Besides, alongside the loss of biodiversity, social assorted variety related with important therapeutic learning is additionally vanishing at a disturbing rate, because of cultural assimilation and urbanization. Therefore, scientists perceive that the answer of the protection of biodiversity lies in a multi-disciplinary and coordinated methodology alongside the fundamental contribution of indigenous. Furthermore, there is additionally a worldwide accord that simple and productive access to data on medical plants information and practices are basic for proficient protection methodologies and the economical utilization of biodiversity [6]. Associations including the United Nations (UN) are scanning for approaches to protect customary learning and find a use for it to help both indigenous and non-indigenous individuals.

Ethnobotany, as the extensive number of educational and medical fields, sites, courses, workshops scholarly projects and media consideration propose, has encountered an unparalleled time of development in the previous twenty years. To be sure, inside this period, "ethnobotany" has been moved out of them to some degree elusive edges of science into the open standard. This renewal of ethnobotany is apparent in post-modern, industrializing and non-industrialized countries, recommending it connect to more extensive auxiliary procedures.

The improvement and make use of databases incorporated with conventional learning is extending. While there's an expected 40 years history of using databases in ethnoscientific subfields (e. g. ethnobotany, ethnobotanics, ethnozoology, ethnopharmacology and so on.) we know nearly nothing of their potential hugeness to indigenous people group. People need to keep up control of a database will probably require self-ruling advancement or community accomplices focused on strategies that stick to social conventions and the insurance of customary learning. While thinking about the significance and potential advancement of a database it is basic to survey its incentive as a computerized innovation. Ethnobotany is recently improved field of the request which is getting more consideration from the academic network in Azerbaijan as of late. There are some distributed works in this field (Fig. 1).

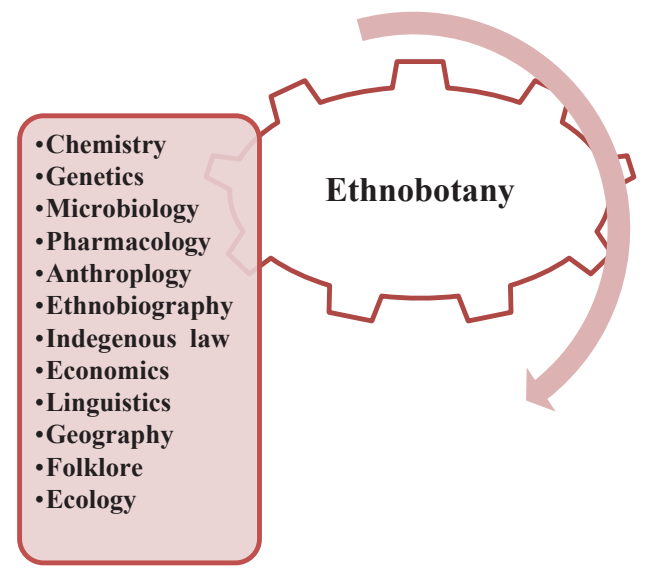

Fig. 1. Fields of related to ethnobotany

The order of ethnobotany has extensive control what is keen on all investigations about the connection among people and plants. Ethnobotany bases around medicinal plants as well as on 
other common items got from nature, for example, nourishment, plants used in ceremonies, fiber plants, harms, building materials for houses, and so on.

\section{Materials and Methods}

\section{1. Using Innovative Systems for Ethnobotanical Information}

Ethnobotany has advanced to address complex human-plant interrelation compare to basic classifying of customarily used plants by people. Ethnobotanical information is urgent for an assortment of logical investigations, for example, pharmacology, veterinary science, biology, and customary learning protection. The obstructions for achieving ethnobotanical data restrict the capacity of analysts and decision-makers producers to address issues in the regions of the investigation, protection, manageable use, and basic leadership. The different idea of accessible ethnobotanical information has presented difficulties for information access, administration, and joining the different ethnobotanical resources. At present, the best way is to use informatics tools to digitize both unpublished and distributed ethnobotanical information (recorded and contemporary) held in different configurations for straightforward entry. A second way is encouraging promotion and consistent mix of information from various areas, for example, scientific classification, environment, phytochemistry, pharmacology, microbiology, and atomic science. Such a coordinated data framework can conceivably corresponding ethnobotanical information with datasets from different controls, along these lines encouraging better comprehension for taking educated choices. For instance, incorporating ethnobotanical data with ordered datasets, for example, the International Plant Name Index will resolve the logical name and related issues concerning ethnobotanical plant types of essentialness [7].

In the ongoing past, there has been an expansion in the accessibility of ethnobotanical information over the web. In spite of an expansion in the number of activities giving information in advanced configurations, for example, public databases and HTML site pages, the aggregate accessible online information are divided and just a little part of what is known. In addition, these endeavors do not equivalent to the measure of gathered ethnobotanical information throughout the hundreds of years and the rate at which it is produced in electronic systems. Further, because of the absence of informatics foundation encouraging simple access and confinements in information administration programming, huge measures of information could not be coordinated, prompting excess and wasteful use. For instance, a database, for example, NAPRALERT, with overall inclusion, gives ethnobotanical data on 20,000 medical plants including some Indian species. In correlation, the Encyclopedia of Indian Medicinal Plants gives ethnobotanical data on 6,198 restorative Indian plant species, yet not these are incorporated into NAPRALERT. Since these datasets are not connected there is no simple method for checking the cover between them. Hence, similarly as with entries, for example, the Global Biodiversity Information Facility (GBIF) information entryway, Species 2000 and ITIS Catalog of Life, the Consortium for the Barcode of Life (CBOL), Australia's Virtual Herbarium (AVH) and the Universal Biological Indexer and Organizer (uBio), a bound together or combined information gateway is required for getting to ethnobotanical data all around [8].

\section{2. The Analysis of some of the Existing Ethnobotanical Databases}

There are a few well-known ethnobotanical databases in our time. While each of these stores has its very own quality, but none has turned a standard form for universal research. The reason is very basic: none of these databases enable specialists to include their own information. Let's use two methods for comparing ethnobotanical databases.

Text mining or content mining is the way toward investigating and examining a lot of unstructured content information supported by programming that can distinguish ideas, designs, subjects, and different traits in the data. Text mining has turned out to be increasingly viable for information researchers and different users because of the improvement of huge information stages [9]. One of the initial phases in the content mining process is composing and structuring the information in some material so it very well may be exposed to both subjective and quantitative analysis. The forthright work incorporates ordering, grouping, condensing informational collec- 
tions, making scientific classifications, and extricating data about things like word frequencies and connections between information substances (Fig. 2).

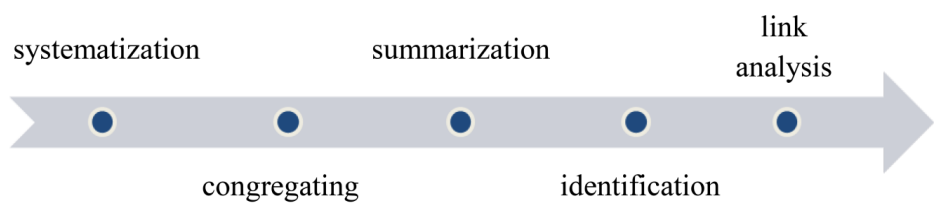

Fig. 2. Text mining steps

Data mining is the way toward dealing with expansive informational collections to distinguish designs and set up connections to take care of issues through information examination. Information mining devices enable institutes or any companies to anticipate future patterns. In information mining, affiliation rules are made by breaking down information for successive on the off chance that designs, utilizing the help and certainty criteria to find the most essential connections inside the information. Support is the means the information show up in the database now and after amending process, while certainty is the occasions if proclamations are accurate. Other data mining parameters incorporate Sequence or Path Analysis, Classification, Clustering and Forecasting. Grouping or Path Analysis parameters search for examples where one occasion prompts another later occasion. A Sequence is an arranged rundown of sets of things, and it is a typical sort of information structure found in numerous databases. A Classification parameter searches new examples, and as a result information is sorted out. Grouping calculations anticipate factors dependent on different factors inside the database [10], (Fig. 3).

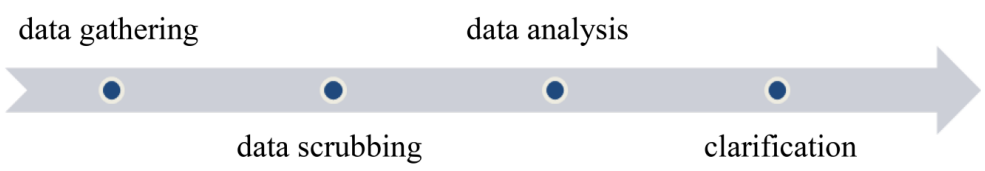

Fig. 3. Data mining steps

There are additionally a few different shortcomings and qualities of every one of these applications.

International Ethnobotany Database is completely multilingual and underpins interpretation, information section, and survey for any dialect. In particular, the database is available to any scientist to include new information, datasets, and dialects. The ebDB is overseen by the Foundation for Open EthnoBotany Research (FOER), an association devoted exclusively to dealing with the database and giving a worldwide store to ethnobotanical information. Therefore, it is protected from institutional political strife and business interests and gives a reliable environment for different information. The biologists have been worked more than four years, and look into the fields of Peru, the ebDB contains an expansive list of capabilities and is structured particularly for ethnobotanical explore [11]. It is completely multilingual, has a glossary, in excess of 20 classes of information, effective searching process, and information send out highlights. Right now, the database preserves information from Ecuador, Peru, Kenya, and Hawai'i. It is the expectation of this venture the ebDB turns into a worldwide standard for putting away ethnobotanical information [11].

Prelude Medicinal Plants Database, this specialized database is identified with the uses of a few plants in customary veterinary and human prescription in Africa. It is helpful for analysts, specialists, veterinary specialists to have documentation available to them that gives access to consolidated data from an assortment of sources in regards to the make use of customary therapeutic plants in various areas of Africa. The point of this database is to address this issue. The data put away in the database is gathered from articles, books, papers given to congresses or straightforwardly to the Prelude Sub-Network on "Well-being, creature preparations, condition".

The information has relegated a data for each plant under the accompanying headings in this database: name of the plant, name of a sort, bibliographical reference, people who were gathered 
ethnobotanical data, vernacular names of the plant. Additionally, it was noted the using qualities of the plants: disease or indication treated, recurrence of use, sort of drug (human or veterinary). There were illustrated 251 different species in Africa [12].

FRLHT Encyclopedia of Indian Medicinal Plants, a database that was prepared on Indian Medicinal Plants is currently accessible for analysts, academicians, students, ethnobotanists, preservationists, nature friends. Thus, FRLHT has been creating in recent years a thorough database on Indian Medicinal Plants. It covers different subject connected to normal assets used by the Indian System of Medicine, for example, natural and common names relationship, geo-dissemination information, maps, exchange data and so on. This is an all-around referenced unique database. This restrictive and creative pursuit based database stores 7,637 herbal names $(6,198$ restorative plants species) with 119183 vernacular names from 12 dialects crosswise over India. Almost 2688 plant pictures are additionally accessible in the database [13].

TradiMed database, in view of different Chinese and Korean therapeutic plants, is the consolidating aftereffect of the conventional drug and the advanced science, which advances comprehension of customary therapeutic medicines from the perspective of the cutting-edge science, and supplements for new improvements of items.

Herbal Taxonomy and Miscellaneous: Aggregate of 3,199 natural data with images, symptoms, adequacy, target organs, property, and well-being measure can be sought by names. What's more, there are 2,944 orders on creatures and herbs.

Formulae: Aggregate of 11,810 medications from 17 works with points of interest, for example, target organs, symptoms, adequacy, readiness, use, alert, reference, and measurement can be recovered.

Constituents (chemical data with range investigation information): Aggregate of around 20,012 constituents from crude materials can be seen with synthetic data, investigative spectrum (UV, NMR, IR, Mass), and conceivable cross-reference.

Manifestation/Disease (cross-reference between the Eastern and the Western medications): Aggregate of 4,080 customary infections are referenced into the cutting edge malady arrangement with titles and side effects.

Preparing: It is the customary technique to plan crude herbs previously use. The aggregate of 95 general processing and 502 herbs are recorded [14].

Dr. Duke's Phytochemical and Ethnobotanical databases' parameters look into accumulated by Dr. Jim Duke of the Green Pharmacy Garden and the United States Department of Agriculture (USDA). The USDA's Agricultural Research Service offers help for the database. Dr. Duke's database has a few key qualities: countless, last information on most database sections, and to reveal concoction data on an assortment of plants. There are 49,788 entities such as phytochemical (biological activity, chemicals, plant, syndrome) and ethnobotanical (ethnobotanical plants and ethnobotanical uses). It is possible to see 13,010 different ethnobotanical plants on this database and their growing place, for what using, common names of some plants. Researchers can also be downloaded data which is necessary for them as pdf or spreadsheet form. Ethnobotanists can find some useful information for pharmaceutical, nutritional, and biomedical research, as well as alternative therapies and herbal products. It additionally has a few basic shortcomings, most strikingly the absence of open information, and restricted help for an assortment of ethnobotany information. The "EthnobotDB" itself just has fields for natural portrayal and use. While this makes the database a successful tool for spreading Dr. Duke's work, it does nothing to help different specialists to viably detail the products of their exploration [15].

A Modern HerbalDatabase was composed in England with an atmosphere like the Pacific Northwest in America, and keeps a top priority.

For Medicinal Use - a primary concern of this database was composed that indigenous people used a plant with true way of thinking of the mid-1900s. This ought to be considered as a portion of the data may now be viewed as erroneous, or not as per the current drug [16].

Plant and Herb Index: More than 800 assortments of herbs and plants.

Record of Recipes: A posting of 29 plants that incorporate formulas.

Record of Poisons: A posting of 44 plants that are recorded as harmful. 
NAPRALERT contains data on a wide assortment of plants and their uses, but its use to scientists start and closure there. In contrast to alternate databases, NAPRALERT is compensation for every framework, with an expense at composing of 8.90 USD per search. While the University of Illinois at Chicago is qualified for reserve its examination, obviously this is no summed up a storage facility for ethnobotanical information. It's essential to likewise take note of that NAPRALERT centers around the phytochemical data for the plants in its database. While phytochemistry is an essential science, with the worries of bio-prospecting it is more dependable to keep phytochemical information separate from unadulterated ethnobotanical information. At last, similar to the previously mentioned two databases, NAPRALERT is monolingual framework [17].

Native American Ethnobotany, a database of plants used medications, sustenance, colors by local Peoples of North America. The online database was a great extent finished in the late 1990s. The database currently contains 44,691 things. This form included nourishments, drugs, colors, strands and different employments of plants (an aggregate of more than 44,000 things). This information was assembled by 291 Native American gatherings of 4,029 species from 243 distinctive plant families. A portion of them is therapeutic. This development of the database was upheld by allowing from the National Science Foundation [18].

The second form of the database was distributed in 1986 by the Museum of Anthropology of the University of Michigan with the title Medicinal Plants of Native America. That database which contained 17,634 things illustrating to the therapeutic employment of 2,147 species from 760 genera and 142 families by 123 diverse local American gatherings - was worked overtime of around 10 years with help from the National Endowment for the Humanities, the National Science Foundation, and the University of Michigan-Dearborn. The information was entered utilizing an intricate plan checking for information uprightness which electronically settled numerous organic equivalent words (which happen when the "same" plant gets diverse logical names, something that frequently occurs over significant lots of time) [18].

A few databases for plant optional metabolic pathways, organic exercises, synthetic structures, ethnobotanical uses, content in nourishments, and pharmacology are open source. A couple of valuable databases are recorded beneath and may keep on filling in as refreshed bases of data.

Table 1

The ethnobotanical databases spreading throughout the world

\begin{tabular}{|c|c|c|}
\hline Ethnobotanical Databases & Links & Languages \\
\hline 1 & 2 & 3 \\
\hline Dictionary of Natural Compounds & http://dnp.chemnetbase.com & English \\
\hline PubChem & http://pubchem.ncbi.nlm.nih.gov & English \\
\hline NAPRALERT & http://www.napralert.org/about.aspx & English \\
\hline $\begin{array}{l}\text { Dr. Dukes's Phytochemical and Ethnobotanical } \\
\text { DB }\end{array}$ & https://phytochem.nal.usda.gov/phytochem/search & English \\
\hline Plant Metabolic Network & http://www.plantcyc.org & \\
\hline USDA databases & $\begin{array}{c}\text { http://fnic.nal.usda.gov/food-composition } \\
\text { /phytonutrients }\end{array}$ & English \\
\hline MetaCYC & http://metacyc.org/ & English \\
\hline Phenol-Explorer & http://phenol-explorer.eu & English \\
\hline Prelude Medicinal Plants Database & www.metafro.be/prelude & English, French \\
\hline FRLHT Encyclopedia of Indian Medicinal Plants & $\begin{array}{l}\text { http://www.frlht.org/newenvis/ } \\
\text { indian-medicinalplants-database.php }\end{array}$ & English \\
\hline Modern Herbal Database & $\begin{array}{c}\text { http://www.botanical.com/botanical/mgmh/ } \\
\text { mgmh.html }\end{array}$ & English \\
\hline International Ethnobotany Database & https://olorien.org/ebDB & English \\
\hline Native American Ethnobotany & http://naeb.brit.org & English \\
\hline
\end{tabular}




\begin{tabular}{|c|c|c|}
\hline 1 & 2 & 3 \\
\hline TradiMed & http://www.tradimed.com & English \\
\hline AGRICOLA & http://www.nal.usda.gov/ag98 & English \\
\hline $\begin{array}{c}\text { The Arctic Science and Technology Information } \\
\text { System database }\end{array}$ & http://www.aina.ucalgary.ca/astis & English, French \\
\hline $\begin{array}{l}\text { Alaska Traditional Knowledge and Native Foods } \\
\text { Database }\end{array}$ & http://www.nativeknowledge.org/start.htm & English \\
\hline American Folk Medicine & http://www.folkmed.ucla.edu/index.html & English \\
\hline Ayurveda & http://www.pharm.uu.nl/home/smit & English \\
\hline BIOSIS & http://www.biosis.org/products_services/ba.html & English \\
\hline CAB HEALTH Database & $\begin{array}{c}\text { http://www.cabi-publishing.org/Products/ } \\
\text { Database/Health/Index.asp }\end{array}$ & English \\
\hline CHIMERA & $\begin{array}{c}\text { http://www.rosenthal.hs.columbia.edu/databases/ } \\
\text { TradMed_CMMRC.html }\end{array}$ & English \\
\hline Crane Herb Company & http://www.craneherb.com & English \\
\hline Economic Botany Bibliographic Database & http://www.kew.org/data/ecbot-biblio.html & English \\
\hline GRIN & http://www.ars-grin.gov/npgs/tax/index.html & $\begin{array}{l}\text { English, Portuguese, } \\
\text { Spanish }\end{array}$ \\
\hline Gernot Katzer's Spice Pages & $\begin{array}{l}\text { http://www-ang.kfunigraz.ac.at/ } \\
\text { ～katzer/engl/index.html }\end{array}$ & English, German \\
\hline HerbMed & http://www.herbmed.org & English \\
\hline Herbal Medicine Databases & http://www.holisticmed.com/www/herbdb.html & English \\
\hline MAROWINA Database & http://www.tropilab.com/medsupp.html & English \\
\hline Medicinal Herbs On-line & http://www.egregore.com/misc/herbindx.htm & English \\
\hline Medicinal Plants Catalogue & $\begin{array}{l}\text { http://www.ayuherbal.com/ } \\
\text { medplantcatalogue.htm }\end{array}$ & $\begin{array}{l}\text { English, French, Ger- } \\
\text { man, Spanish }\end{array}$ \\
\hline Rainforest Tropical Plant Database & http://www.rain-tree.com/plants.htm & $\begin{array}{l}\text { English, French, Ger- } \\
\text { man, Italian, Norwegian, } \\
\text { Portuguese, Spanish }\end{array}$ \\
\hline TRAMIL Medicinal Plant Database & http://www.funredes.org/tramil & English, French, Spanish \\
\hline
\end{tabular}

Source: https://www.wipo.int/edocs/mdocs/tk/en/wipo_grtkf_ic_3/wipo_grtkf_ic_3_6-main1.pdf

It is illustrated the diagram that consist of the percentage of ethnobotanical databases existing in the different countries according to their using more by experts and users (Fig. 4).

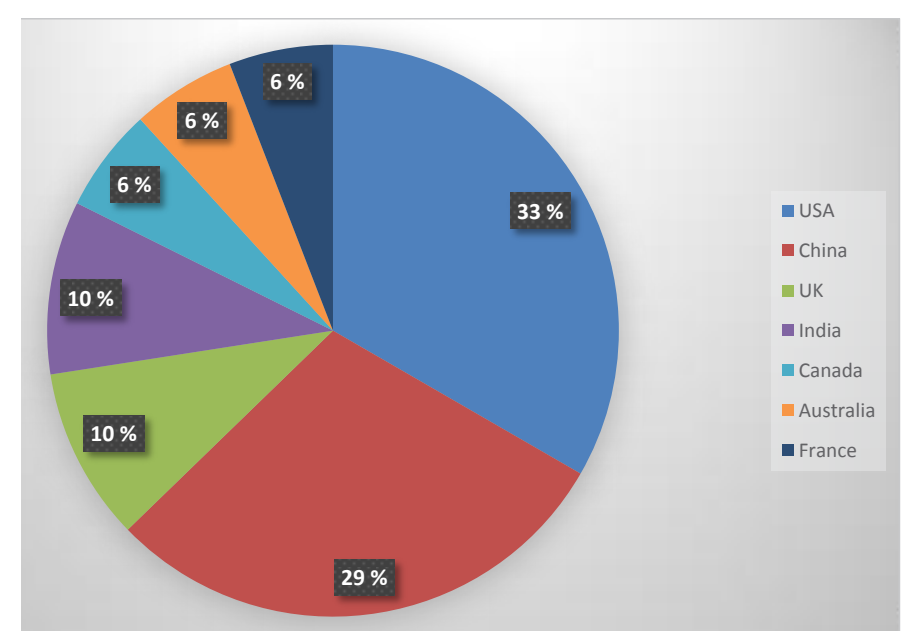

Fig. 4. The percentages of using ehnobotanical databases according to countries Source: https://www.wipo.int/edocs/mdocs/tk/en/wipo_grtkf_ic_3/wipo_grtkf_ic_3_6-main1.pdf 


\section{Results}

\section{1. The Determination of Structure and Schematic Illustration of the Ethnobotanical} Database

The database model has been executed as a local database. Distinctive execution arrangements were tried, as indicated by the prerequisites and find a use for cases. Present and old ethnobotanical information was composed in a similar table structure, permitting a few expenses of excess for the homogenization of information and inquiries. Since adaptability was a noteworthy issue for our file, the questions were situated center of ideas which were actualized, for example, boundless various leveled structures, especially for classified tables and scientific species categorization, and legacy ideas, being a reference to data sources, a person, a natural or an archeological remain. Those procedures enabled individuals to build up an insignificant information structure fitting diverse sort of data and to perform questions at various levels of detail (Fig. 5).

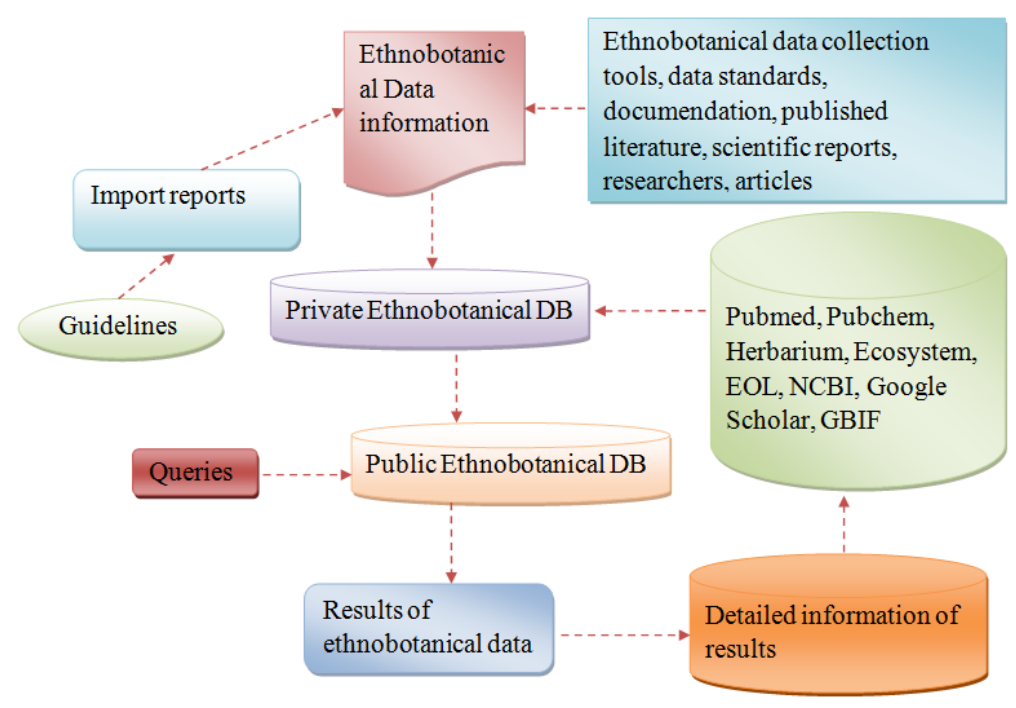

Fig. 5. A schematic illustration of the key components of the ethnobotanical database

The document presently permits the capacity and administration of ethnobotanical data from sources, recorded herbarium examples and archives, as indicated by a various leveled inventory of plant uses and arrangements (therapeutic, nutritious, stylized, veterinary, local, medical, food). It is additionally conceivable to incorporate ethnobotanical data from archeological remains, in spite of the fact that the connections to the relative databases have not yet been executed. Plants' names data: plant prevalent names (local, botanical, ancient), and their relationship with species scientific classification.

Ethnobotanical information was composed in a social structure: an identified table can gather data on various plants, which can be used for various degrees. Conventional learning can't be effectively ordered and remedial utilizations are regularly intermixed with formal and representative ones. Be that as it may, to permit a more compelling hunt inside the database, convictions, and works on managing people employments of an animal varieties were assembled being used classifications, going over restorative (counting warmth and method of organization of the plant), formal (representative, custom, religious including any conviction concerning the plant), wholesome, local, veterinary employment. These classifications have been sorted out in a various leveled structure and might be relegated by the detail level of the data accumulated. A dependability level of those utilization assignments is given, especially for information from the antiquated treatises and from archeological remains. The guideline of putting away data with various levels of exactness has been executed additionally for the arrangement steps and for the plant parts included (Fig. 6).

Data sources can be numerous sorts, in particular, bibliographic references, gatherers, herbals or archeological remains. All or subsets of these sorts can be referenced, as indicated by the tables where a source data is required. 

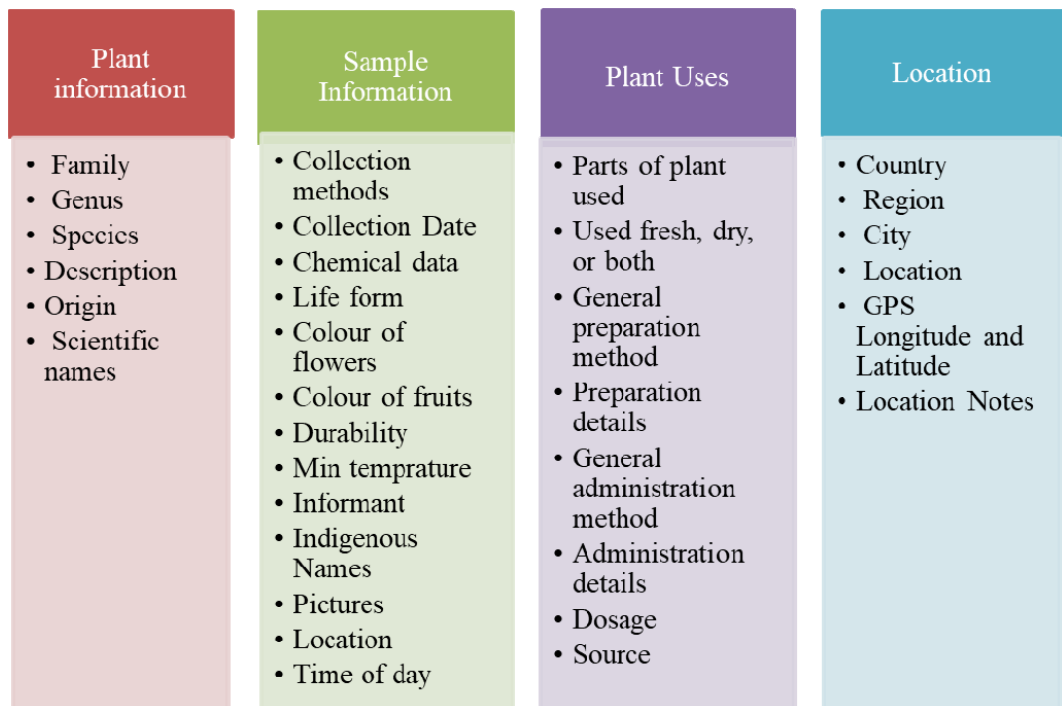

Fig. 6. The structure and main tables of the ethnobotanical database

The database of medicinal plants for plant biodiversity conservation was prepared for Azerbaijan nature. The database consists of 178 families, 740 genera, 1547 species which grow in Azerbaijan. It was observed when analyzing this database that $34.3 \%$ plants are medicinal plant among 4500 plant species. Each species has 24 parameters which reflect the whole taxonomic characteristics, ecology, the territory of distribution, contents of the biologically active compounds, application forms, therapeutic properties, the status of plant species as endemics, relicts, rarity, references, their photographs in natural ecosystems. Among these medicinal plants, 77 herbal plants species are Caucasian endemics, 5 species are national endemics, 44 species are relicts, 112 medicinal species are rare and endangered. The collected information on different herbs gives valid data on its high assorted variety and endemism, and also information on scarce and endangered plant species in the certain districts of the nation. It permits to effectively make an oversee framework to characterize the conveyance and centralization of biodiversity spots of herbs and to apportion the regions, particularly critical for conservation [19].

It is planned to create a new information system for Azerbaijani ethnobotanical plants which used OLAP (Online Analytical Processing) technology for illustrating ethnobotanical data about plants. As a result, it will be possible to find plant information according to years, medical and chemical properties, also to evaluate various components of multidimensional information.

\section{Conclusions}

Massive ethnobotanical information having social hugeness and financial esteem is conveyed among various indigenous peoples and research associations. Licensed innovation rights are vital for tending to worldwide issues, for example, decreasing biodiversity, sustenance security, lessening conventional learning and the requirement for new prescriptions to battle expanding drug obstruction.

While a few ethnobotanical databases exist, none are satisfactory answers for worldwide work, and none enable analysts to include their very own information. There is a need brought together all essential properties of existing databases, and creating a free database that encourages ethnobotanical research. Due to the rise and quick improvement in the field of data advances, it has now turned out to be conceivable to digitize, oversee and make ethnobotanical information accessible to a more extensive gathering of people.

By grasping the intensity of innovation data, ethnobotanists and decision-makers can connect the substantial gap between the created databases. The way to accomplishing these objectives would be the inception of communitarian associations and familiarity with the centrality of IT among ethnobotanists, indigenous peoples and decision-makers from different nations. It is vital to guarantee protection and reasonable find a use for this data for human prosperity. 


\section{Acknowledgements}

I would like to thank my advisor, DScTech Rasim Mahammad Alguliyev, PhD Farhad Firudin Yusifov and Phd Naiba Pirverdi Mehtiyeva for lots of great inspiration, ideas, comments, and feedbacks. I certainly could not have completed this article without their expertise and advice.

\section{References}

[1] Ahmed, H. M. (2016). Ethnopharmacobotanical study on the medicinal plants used by herbalists in Sulaymaniyah Province, Kurdistan, Iraq. Journal of Ethnobiology and Ethnomedicine, 12 (1). doi: https:// doi.org/10.1186/s13002-016-0081-3

[2] Baydoun, S., Chalak, L., Dalleh, H., Arnold, N. (2015). Ethnopharmacological survey of medicinal plants used in traditional medicine by the communities of Mount Hermon, Lebanon. Journal of Ethnopharmacology, 173, 139-156. doi: https://doi.org/10.1016/j.jep.2015.06.052

[3] WHO Traditional Medicine Strategy: 2014-2023 (2013). Geneva: World Health Organization, 76.

[4] Sarkar, I. N. (2007). Biodiversity informatics: organizing and linking information across the spectrum of life. Briefings in Bioinformatics, 8 (5), 347-357. doi: https://doi.org/10.1093/bib/bbm037

[5] Mehdiyeva, N. P., Guliyev, I. S., Alizade, V. M., Alirzayeva, E. H., Bussmann, R. W. (2017). Ethnobotany of the Caucasus - Azerbaijan. Ethnobotany of the Caucasus, 37-46. doi: https://doi.org/10.1007/9783-319-49412-8_16

[6] Maryo, M., Nemomissa. S., Bekele, T. (2015). An ethnobotanical study of medicinal plants of the Kembatta ethnic group in Enset-based agricultural landscape of Kembatta Tembaro (KT) Zone, Southern Ethiopia. Asian Journal of Plant Science and Research, 5 (7), 42-61.

[7] Buenz, E., Schnepple, D., Bauer, B., Elkin, P., Riddle, J., Motley, T. (2004). Techniques: Bioprospecting historical herbal texts by hunting for new leads in old tomes. Trends in Pharmacological Sciences, 25 (9), 494-498. doi: https://doi.org/10.1016/j.tips.2004.07.003

[8] Buneman, P. (2005). What the Web Has Done for Scientific Data - and What It Hasn't. Lecture Notes in Computer Science, 1-7. doi: https://doi.org/10.1007/11563952_1

[9] Shinde, P., Govilkar, S. (2015). A Systematic study of Text Mining Techniques. International Journal on Natural Language Computing, 4 (4), 54-62. doi: https://doi.org/10.5121/ijnlc.2015.4405

[10] Haripriya, P., Porkodi, R. (2016). A Survey Paper on Data mining Techniques and Challenges in Distributed DICOM. International Journal of Advanced Research in Computer and Communication Engineering, 5 (3), 741-747.

[11] International Ethnobotany Database. Available at: https://olorien.org/ebDB

[12] Prelude Medicinal Plants Database. Available at: https://www.africamuseum.be/research/collections_libraries/biology/prelude

[13] FRLHT Encyclopedia of Indian Medicinal Plants. Available at: http://www.frlht.org/newenvis/ indian-medicinalplants-database.php

[14] TradiMed. Available at: http://www.tradimed.com/

[15] Dr. Duke's Phytochemical and Ethnobotanical Databases. Available at: https://phytochem.nal. usda.gov/phytochem/search

[16] A Modern Herbal Database. Available at: http://www.botanical.com/botanical/mgmh/mgmh.html

[17] NAPRALERT. Available at: https://napralert.org/

[18] Native American Ethnobotany. Available at: http://naeb.brit.org/

[19] Mehtiyeva, N. (2013). Importance database of medicinal plants for plant biodiversity conservation in Azerbaijan. International conference, Environmental changes conservation of plant diversity. 